\title{
DIMENSIONAL ACCURACY OF DIRECT AND INDIRECT IMPLANT IMPRESSION TECHNIQUES FOR COMPLETELY EDENTULOUS PATIENTS
}

\author{
Yasmeen Fat'hy Al-Mahdy*; Hala Mohamed Gamal El Din* and Dina Mahmoud Kholief*
}

\begin{abstract}
Background: Accurate recording of implant location is required for a successful definitive restoration.

Aim: This study was conducted to compare the accuracy of two implant impression techniques (direct and indirect) in transferring implant positions to the master casts in comparison to implant position in patients' mouth using radiographic imaging.

Materials and Methods: Ten completely edentulous male patients were selected. 2 Root-form implants $3.7 \mathrm{~mm}$ in diameter and $16 \mathrm{~mm}$ in length were utilized in this study in the canine regions. For each patient two special trays were fabricated, one for the registration of direct impression technique and the other for the indirect impression technique. Cone beam computed tomography (CBCT radiograph) was done for all patients, the casts obtained from direct and indirect implant impression techniques were taken to evaluate the accuracy of the two impression techniques in comparison with the patients' radiographs regarding the distance between the implants. The horizontal dimensional accuracy of the impression techniques was determined by measuring the inter-implants' distance in the $\mathrm{x}$-axis between the copings. Measurements were done on radiographic images of the following; casts obtained from direct impression technique, casts obtained from indirect implant impression technique and radiographs of patients.
\end{abstract}

Results: The mean and SD values of casts radiographs obtained from both impression techniques and from patients' radiographs were calculated. Group I (Deviation of distance between direct impression technique and patients' radiograph) had a mean value of $1.45 \mathrm{~mm}$ (SD 0.03); Group II (Deviation of distance between indirect impression technique and patients' radiograph) had a mean value of $2.08 \mathrm{~mm}$ (SD 0.04). The direct impression technique showed more accurate results.

Conclusion: Casts obtained from the direct impression technique were significantly more accurate than those obtained from indirect impression technique. Comparison of both impression techniques retrieved from patients in relation to patients' $\mathrm{CBCT}$ provided more reliable results than in vitro studies. So this study suggests that direct impression technique is more accurate.

KEY WORDS: impression coping, impression technique, impression accuracy, implant misfit, direct impression technique, indirect impression technique.

*Assistant Professor of Removable Prosthodontics, Faculty of Dental Medicine (girls' branch), AlAzhar University. 


\section{INTRODUCTION}

Recently, dental implants have been widely used for the rehabilitation of partially and completely edentulous areas. Dental implants can be used to retain single crowns, fixed partial dentures, full arch bridge and removable prostheses. The use of dental implants is now well established and high survival rates have been reported. Implant dentistry now forms a significant part of general dental practice and patient awareness is progressively increasing (1-7)

The success of implant-supported restorations relies on how well hard and soft tissue information is transferred to the laboratory ${ }^{(8)}$. The accuracy of dental impressions of the implant position and surrounding hard and soft tissues is essential to fabricating an esthetic and biologically functional final restoration. Obtaining an accurate impression is influenced by a several factors, including number of implants, implant angulation, use of coping splinting, material choice, type of impression trays and impression copings used ${ }^{(9-12)}$.

An accurate implant impression is a vital prerequisite for obtaining an accurate master cast which is the key for the fabricating an accurately fitting successful prosthesis. However, dimensional changes occur due to the contraction in the impression material which is initiated by polymerization reaction with formation of volatile materials and by-products, pressure applied during impression and impression techniques. Making a precise mold of implant is necessary for passive fitness in which implant body shows adequate fitting for simultaneous adaptation and remodeling ${ }^{(13-15)}$.

Making a superstructure with passive fitness is one of the main objectives during implant-based prosthesis (16). However, Errors in the implant impression procedure during the fabrication of the definitive cast can cause misfit of the implant superstructure which increases the risk of biologic and mechanical failures ${ }^{(4,17,18)}$. It was stated that the forces created in the implant due to non-passive nature of the superstructure is able to establish stresses at the implant/bone interface which may eventually lead to fixture loosening, abutment and restoration fracture ${ }^{(19,20)}$. Also, it causes ischemia within peri-implant tissue and subsequent healing with non-mineral tissue around the implant which may subsequently lead to resorption of the bone surrounding the implant. Therefore, failing to achieve passive fitness will incur stress on implants which can finally lead to failure of the treatment (16). Thus, the fabrication of a precise definitive cast that exactly transfers the intraoral position of the implant or abutment is essential for the long-term stability of the implant prosthesis ${ }^{(21)}$.

In implant dentistry, several impression techniques have been advocated to achieve a definitive cast that will ensure the passive fit of prosthesis on osseointegrated implants. The two basic impression techniques that are currently in use for transferring implant positions from the mouth to the cast include direct (also known as pick-up or open tray impression techniques because the tray has an open window for unscrewing the guide pins of the impression copings.) and indirect (also known as transfer or closed tray impression techniques) ${ }^{(8}$, 22). In the direct impression technique, impression copings remain in the impression while it is removed from the mouth. Conversely, in the indirect impression technique, copings remain attached to the implants intraorally when the impression is removed from mouth and are transferred to the impression in a second step ${ }^{(23)}$.

The indirect technique may be less difficult clinically; however, it has been shown to have greater instability in transferring the implant position. In the direct technique the impression coping lies within the impression so this reduces the effect of implant angulation, the deformation of the impression material upon recovery from mouth and removes the concern for replacing the coping back 
into its respective space in the impression ${ }^{(24)}$.

Studies have found no preferences in terms of the impression technique used ${ }^{(9,25)}$. Both the direct and indirect techniques are routinely used in dental practice ${ }^{(26)}$. Some researchers favored direct impression technique as they claimed that the relationship between the impression coping and the bulk of impression material is critical to accuracy, especially when the implant analog and the impression coping are assembled before pouring the cast ${ }^{(20,27-29)}$. The use of indirect impression technique was chosen by other investigators as it is more effective in certain clinical situations, including patients with limited inter-arch space, a strong gag reflex, or limited mouth opening where access to the implant fixture is difficult ${ }^{(8)}$. In addition to that, indirect technique is an easy and simple technique ideal for single implant impressions and multiple parallel implants in patients with limited mouth opening ${ }^{(30)}$.

Most research work regarding accuracy of implant impression techniques are done in vitro on casts, however, this study is among few research work that is done on patients. The purpose of this study is to compare the accuracy of two implant impression techniques (direct and indirect) in transferring implant positions to the master casts in comparison to implant position in patients' mouth using radiographic imaging.

The null hypotheses proposed that no dimensional difference will result between the casts fabricated from the direct and indirect impression techniques in comparison to radiographic image of the patient.

\section{SUBJECTS AND METHODS}

Study sample: Ten completely edentulous male patients were selected from the Out-Patient Clinic of Prosthodontic Department; Faculty of Dental Medicine, Al-Azhar University, Girls' Branch. Patients' age ranged from 50-65 years, they were free from systemic diseases that might interfere with osseointegration of implants or contraindicate surgical procedures as:

1. Uncontrolled diabetes.

2. Hemophilia, bleeding disorders or anticoagulant therapy.

3. Metabolic bone disorders.

4. Patients affected by sever chronic renal or hepatic diseases.

5. Heavy smokers.

6. Patients recently received local radiotherapy to the head and neck region.

In addition, psychiatric handicaps who cannot tolerate long surgical procedures or maintain good oral hygiene and patients with high frenal or muscle attachment, macroglossia or tight lower lip were also excluded.

\section{Methods:}

Patient examination: Thorough medical and dental history were taken from the patients, each patient was asked about the date and cause of extraction of the last mandibular canine which should be at least 6 months before insertion of the implants. Construction of radiographic template with two metal standardized marking spheres of $4 \mathrm{~mm}$ diameter fixed at canine areas on each side of the transparent template was done. After that, Cone beam computed tomography (CBCT) (Planmeca Promax $3 \mathrm{D}$, Finland) radiographs were carried-out for every patient with the template in place showing the position of the balls (implant potential site). After the preoperative radiographs were taken, the radiographic template was modified to a surgical template by removing the metallic spheres and making circular holes at the canine areas on each side of the transparent template.

Surgical procedures: 2 Root-form implants 3.7 $\mathrm{mm}$ in diameter and $16 \mathrm{~mm}$ in length (Legacy $1 \mathrm{im}$ plant Direct LLC, Malibu Hills, CA 91301, USA) 
were utilized in this study in the canine regions. The surgical stent was firmly seated over the mandibular residual ridge for starting the surgical preparation with pilot drill through the surgical guide at the previously determined implant site, the following drill $2.3 \mathrm{~mm}$ diameter was used to widen the osteotomy site till it reached $16 \mathrm{~mm}$ in depth then followed by $2.8 \mathrm{~mm}$ drill diameter and the final drill used was $3.4 \mathrm{~mm}$ diameter. The drilling speed was adjusted at 1100 revolutions per minute (RPM) and the reduction hand piece (1:16) was used for the preparation of the osteotomy sites; parallelism was verified using paralleling rods. The implants were inserted manually then by the ratchet until the implants top flushed with the alveolar bone surface. Healing abutments were screwed into the implants using the hex driver. The patients were instructed to eat soft diet and not to wear their old dentures only for one week and to perform meticulous oral hygiene measures. Three months after surgery patients were inspected for osseointegration.

Prosthetic treatment: For each patient, conventional upper denture and lower implant retained complete denture were constructed following the conventional procedures. For each patient two special trays were fabricated, one for the direct impression technique and the other for the indirect impression technique as follows:

\section{Direct (open-tray) impression technique:}

The implant areas on cast were covered by two layers of baseplate wax to allow uniform thickness of impression material. The custom trays were made with autopolymerizing acrylic resin and shortened 2 $\mathrm{mm}$ in the periphery. The trays were perforated in the region where implants were placed to provide access for the pick-up copings.

After healing abutment was removed, the transfer copings were seated into the implant fixtures and then secured into position by screwing the impression posts into the fixtures in the patient's mouth. Two holes of $6 \mathrm{~mm}$ diameter were perforated in the exact implant position of the tray to provide adequate spaces for the transfer copings. The impression tray was evaluated intraorally to ensure that it was well adapted and that all the impression copings protrude through the openings in the tray without contacting the acrylic resin tray. The tray was then border molded with green stick compound. The impression copings were placed into the implant. The impression posts were tightened using the screwdriver. The regular body polyvinylsiloxane impression material (Elite P\&P Regular body, Zhermack SpA, Italy) was loaded inside the impression tray and some impression material was meticulously syringed around the impression copings to ensure complete coverage of the copings with the copings and posts passing through the holes.

After setting, the screwdriver was used to loosen the impression copings. Then the impression; together with the copings in position; was completely removed. The corresponding fixture analogs were threaded into the impression posts before pouring the impression into hard stone using double pouring technique.

\section{Indirect (Closed tray) impression technique:}

Healing abutment was removed, then the impression copings were placed into the implants and the guide screw were tightened using screwdriver. The regular body polyvinylsiloxane impression material was loaded inside the impression tray as well as around the impression copings. Once the material was set, tray was removed from the patient's mouth. Impression copings were unscrewed and removed from the patient's mouth and were mounted onto the analogs using the guide screw and then repositioned in the impression. The impression copings were gently pushed until a tactile response of engagement is felt. The impression was then poured into hard stone using double pouring technique. 
Each impression of both techniques was examined and it was repeated when any kind of deficiency was observed including trapped air bubbles and leftovers of impression material between the coping connection and the analog.

\section{Complete denture construction and pick up tech- nique of abutment:}

The complete denture procedures were completed until the patient delivered an upper complete denture and lower implant retained complete overdenture.

The healing abutments were removed, ball abutments were placed onto each implant using hex driver. The metal housings with the nylon liners were attached to the male ball abutments, and a chair side auto-polymerized acrylic resin was used for direct pick-up of the attachments, the patient was instructed to close in the centric occluding relation with gentle biting force until complete polymerization of the acrylic resin occurred. The overdenture was removed from the patient's mouth; excess material around the metal housings was trimmed. Any roughness or irregularities were removed, finished, polished and delivered to the patients.

\section{Cone Beam Computed Tomography (CBCT) as- sessment:}

CBCT for all patients and casts obtained from direct and indirect implant impression techniques were taken to evaluate the accuracy of the two impression techniques in comparison with the patients' radiographs.

In order to ensure standardization and that all patients and casts produced from both impression techniques were positioned on the same relative plane and put at same distance to film position, digitalization of implant positions were done using CBCT scanning to facilitate accurate linear measurements between both copings in casts and patients.

\section{Evaluation of dimensional accuracy:}

The horizontal dimensional accuracy of the impression techniques was determined by measuring the inter-implants' distance in the $\mathrm{x}$-axis between the copings using certain reference points (at the junction point between the implant fixture and the abutment in the patients' radiographs, and at the junction point between the implant fixture and the copings in the casts radiographs). Measurements were done on radiographic images of patients (fig. 1), casts obtained from direct implant impression technique (fig. 2) and indirect implant impression techniques (fig. 3). All measurements were made 5 times for each reading and the mean value was considered.

Next, deviation of distances between implants in the stone casts produced by the two impression techniques in relation to the patient radiograph was calculated by subtraction of distance in cast

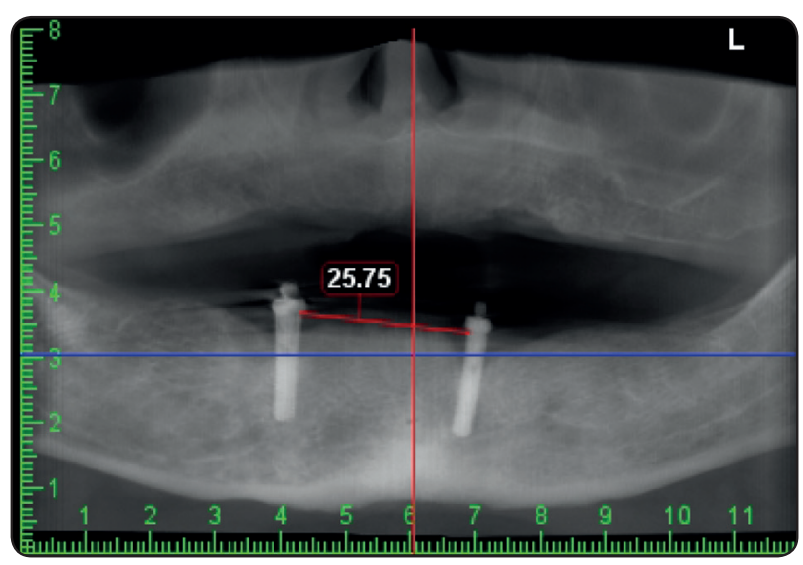

Fig. (1) Distance (mm) measured between implants in patient's radiograph.

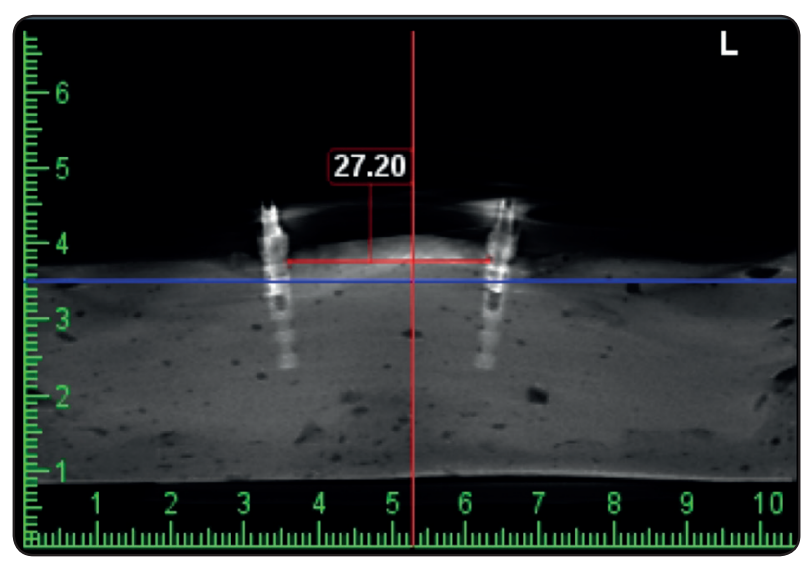

Fig. (2) Distance ( $\mathrm{mm})$ measured between implants in radiograph image of cast obtained from direct impression technique. 


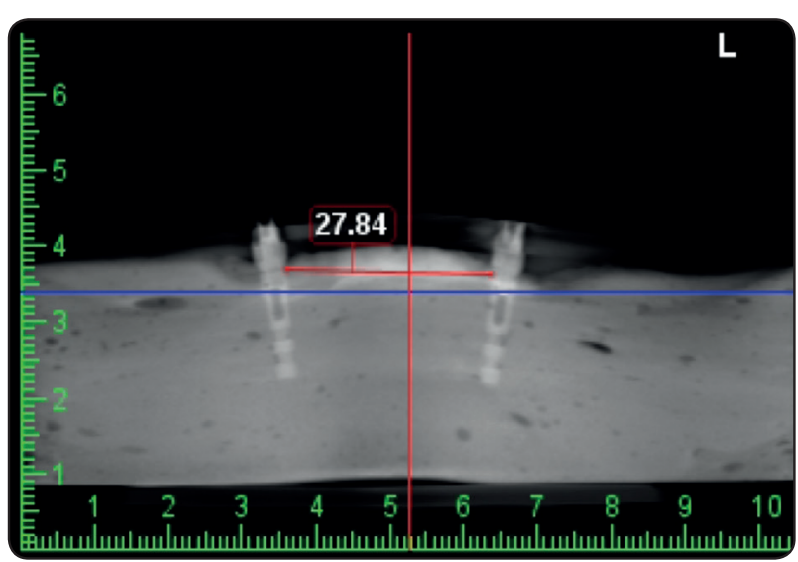

Fig. (3) Distance ( $\mathrm{mm})$ measured between implants in radiograph image of cast obtained from indirect impression technique.

radiograph to distance in patients radiograph. This procedure was done with all ten patients.

For standardization purpose, all measurements were made by a single operator to avoid inter operator error.

\section{Statistical analysis:}

The data were collected, tabulated, statistically analyzed and presented as descriptive statistics (means and standard deviations). Data were explored for normality using Kolmogorov-Smirnov test of normality. The results of Kolmogorov-Smirnov test indicated that most of data were normally distributed (parametric data), Difference in accuracy between patient's radiograph and the cast radiograph obtained from direct impression technique is designated as
Group I, while Difference in accuracy between patient's radiograph and the cast radiograph obtained from indirect impression technique is designated as Group II. The two groups were analyzed using paired t-test between the two groups regarding distance deviation of casts radiographs from patients' radiographic measurement. P-values less than 0.05 were considered statistically significant. Statistical analysis was performed with SPSS 16.0 (statistical package for scientific studies, SPSS, Inc., Chicago, IL, USA) for windows.

\section{RESULTS}

The mean and SD values of casts radiographs obtained from both impression techniques and from patients' radiographs were calculated and presented in (Table 1 and figure 4): Group I (Deviation of distance between Direct impression technique and patients' radiograph) had a mean value of $1.45 \mathrm{~mm}$ (SD 0.03); Group II (Deviation of distance between indirect impression technique and patients' radiograph) had a mean value of $2.08 \mathrm{~mm}$ (SD $0.04)$. The values are reported along $x$-axis. When comparing both groups, there was a statistically significant difference between them. The direct impression technique showed less deviation of distance in relation to patients' radiographs, hence direct impression technique showed more accurate results.

TABLE (1): The mean, standard deviation and results of accuracy comparison of direct and indirect impression techniques in relation to patients $(\mathrm{mm})$.

\begin{tabular}{|c|c|c|c|c|c|}
\hline & Group I & Group II & \multirow{2}{*}{ Mean difference } & \multicolumn{2}{|c|}{ Paired t-test } \\
\cline { 2 - 3 } & Mean \pm SD & Mean \pm SD & & t-value & p-value \\
\hline Mean \pm SD & $1.45 \pm 0.03$ & $2.08 \pm 0.04$ & \multirow{2}{*}{$0.63 \pm 0.018$} & 105.654 & $0.000^{*}$ \\
\hline Range & $1.40-1.50$ & $2.02-2.14$ & & & \\
\hline
\end{tabular}

Group I: Deviation of distance between direct impression technique and patients' radiograph.

Group II: Deviation of distance between indirect impression technique and patients' radiograph.

*: Significant at $P \leq 0.05$ 


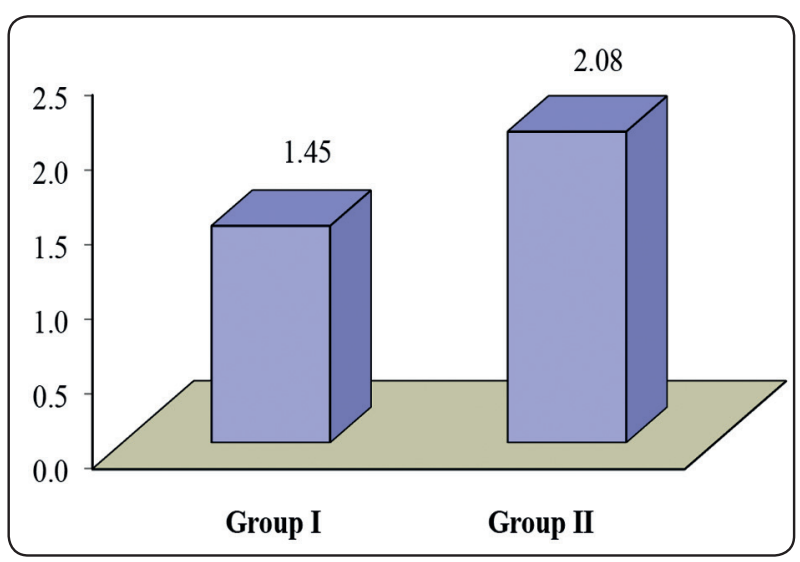

Fig. (4): Accuracy comparison of direct and Indirect Impression Techniques in relation to patients.

\section{DISCUSSION}

Clinical experiences emphasize the importance of passive fit of the prosthetic superstructure on multiple implants. Inaccurate fit of the superstructure causes both mechanical and biologic consequences that disrupt continuous function of dental implants. An important factor that influences precision of fit is making an accurate impression that precisely transfers the intra-oral position between the implants in all dimensions ${ }^{(31-33)}$.

Because the precise transfer of the three dimensional intraoral relationships of implants from the mouth to the master cast is a critical step to achieve a passive fit ${ }^{(34)}$, choosing impression material, impression technique and pouring technique was done meticulously. Various impression materials were recommended by many authors but polyvinylsiloxane and polyether both are the material of choice for making accurate impression ${ }^{(35)}$. Some studies claimed that no significant differences were established regarding the choice of impression material ${ }^{(36)}$. In addition to that, it was claimed that the accuracy of implant impressions is not affected by the type of impression material for both partially and completely edentulous patients ${ }^{(15)}$. In this study, polyvinylsiloxane was chosen as an impression material because it was suggested to be more accurate with respect to polyether ${ }^{(37)}$. The double pouring technique was used in this study to minimize the stone volumetric expansion for more accurate results ${ }^{(38)}$.

Several impression techniques have been advocated for implant impressions to obtain definitive casts. The selection of an appropriate impression technique depends upon various clinical situations such as number of implants, splinting impression copings ${ }^{(9)}$, implant angulation ${ }^{(39,40)}$, polymerization shrinkage of the impression material, setting expansion of the dental stone, and the design and rigidity of the impression tray, position in arch, interarch space and operator's choice ${ }^{(41-43)}$.

The two main impression techniques that are mostly used during implant impression are direct and indirect impression techniques. Therefore, many studies have compared the accuracy of both impression techniques and the results were widely variable. Some studies found no difference between both of them ${ }^{(20,44-46)}$, some favored the direct impression technique ${ }^{(47-49)}$ and others showed that the indirect technique had superior results ${ }^{(26,50,51)}$.

Many studies showed that number of implants affects the accuracy of the impression technique used. Several investigations advocated the direct impression technique when four or more implants are employed ${ }^{(52-55)}$. Other investigations agreed that direct impression technique is preferred in multiple implants with different angulations ${ }^{(9,30,45)}$. On the other hand, when using less than four implants, some studies advocated the direct impression technique ${ }^{(56-57)}$ and others showed no differences between both techniques ${ }^{58,59)}$.

Most investigations regarding accuracy of implant impression techniques are done in vitro on casts, however, in our study, the master casts were retrieved from an actual patient treatment to give actual and more reliable results about accuracy of impression techniques. It was claimed that discrepancies between direct and indirect 
impression techniques in the in vivo study were six times higher than the results reported in the in vitro study ${ }^{(60)}$ which explains the higher deviation values in this study than other in vitro studies. To ensure accuracy of measurements, Cone beam computed tomography was used in this study as it is highly accurate and reproducible in linear measurements in the axial and coronal image planes, and in different areas of the maxillofacial region ${ }^{(61)}$.

In this study, the distance between implants in the casts of both impression techniques showed an increase than the patients' radiographs. Although the increase was not massive for both techniques, it was verified that the inaccuracies were in the indirect impression technique. Therefore, this study revealed that direct impression technique showed higher accuracy than indirect impression technique when results of both techniques were compared with the patients radiographs. Deviation of distance between Direct impression technique and patients' radiograph had a mean value of $1.45 \mathrm{~mm}$ (SD 0.03 ), while Deviation of distance between indirect impression technique and patients' radiograph had a mean value of $2.08 \mathrm{~mm}$ (SD 0.04). These results are consistent with many investigations that found that the direct impression technique is more accurate than the indirect impression technique ${ }^{(9,33,35,62)}$. This may be explained by that in the direct impression technique, the impression coping lies within the impression and this may lead to minimization of dimensional changes in impression upon removal from patient's mouth. Furthermore, there is no need to screw in coping again as it comes along with the impression ${ }^{(30)}$. Moreover, the inaccuracy of the indirect technique may arise from nonparallel implants or from the apparent deformation of a stiff impression material such as polyether. Therefore, a more elastic impression material could hypothetically reduce the permanent deformation of the impression. As the impression coping of the direct technique remains in the impression, the effect of the implant angulation and the deformation of the impression material upon recovery from the mouth will be reduced ${ }^{(20,48)}$. Also, the primary source of error in the indirect impression technique is that there are more chances of dimensional changes upon removal from patient's mouth with angulated implants and that copings never returned to the original position and this error is increased in case of impression with multiple implants leading to inaccuracies. Also, the indirect technique had discrepancies in axial rotation and inclination of the analogs ${ }^{(30,35)}$.

In a systematic review comparing between impression techniques for partially and completely edentulous patients, it has been stated that direct impressions were found to be more accurate than indirect impressions for patients with complete edentulism, however, it was stated that there is no difference in accuracy between direct and indirect impression techniques for partially edentulous patients ${ }^{(15)}$.

In contrary to our study, It was found that there are many controlling parts during screwing, some spatial movement of the impression coping while screwing in of implant analog, and blind screwing of the implant analog to the impression coping resulting in misfit of components as well as screwing of the analog to the coping is done visually. These factors favored the use of indirect impression technique by some authors $(26,30,50,51)$.

Conversely, in a study made to determine which impression techniques resulted in the least three dimensional displacement of implant position, it was found that there was no significant difference between the direct and indirect impression techniques ${ }^{(63)}$. Also, the results of a previous study showed that although significant difference was found in the y-direction between direct and indirect impression techniques, there was no statistical significant difference in whole dimensions, which is inconsistent with several other investigations ${ }^{(20)}$.

These widely different results are likely due to the use of different components and study designs ${ }^{(64)}$. 


\section{CONCLUSION}

Within the limitations of the present study, it could be concluded that:

1. Comparison of both impression techniques retrieved from patients in relation to patients' CBCT provided more reliable results than in vitro studies.

2. Impression technique influences accuracy of implant transfers.

3- Casts obtained from the direct impression technique were significantly more accurate than those obtained from indirect impression technique.

\section{REFERENCES}

1. Scheller H, Urgell J, Kultje C, Klineberg I, Goldberg PV, Stevenson-Moore P, Alonso JM, Schaller M, Corria RM, Engquist B, Toreskog S, Kastenbaum F, Smith CR. A 5-year multicentre study on implant supported single crown restorations. Int J Oral Maxillofac Implants 1998; 13(2): 212-218.

2. Levin L, Laviv A, Schwartz-Arad D. Long term success of implants replacing a single molar. J Periodontol 2006; 77(9): 1528-1532.

3. Levin L, Sadet P, Grossmann Y. A retrospective evaluation of 1,387 single tooth implants: a 6-year follow up. J Periodontol 2006; 77(12): 2080-2083.

4. Pjetursson BE, Tan K, Lang NP, Brägger U, Egger M, Zwahlen M. Systematic review of the survival and complication rates of fixed partial dentures (FPDs) after an observation period of at least 5 years. Clin Oral Implant Res 2004; 15(6): 625-642.

5. Brånemark PI, Svensson B, van Steenberghe D. Ten year survival rates of fixed prostheses on four or six implants ad modum Brånemark in full edentulism. Clin Oral Implant Res 1995; 6(4): 227-231.

6. Sadowsky SJ. Treatment considerations for maxillary implant overdentures: a systematic review. J Prosthet Dent 2007; 97(6): 340-348.

7. Seyedan K, Sazegara H, Kalalipour M, Alavi K. Dimensional Accuracy of Polyether and Poly Vinyl Siloxane Materials for Different Implant Impression Technique. Res J Appl Scien 2008; 3(3): 257-263.
8. Bhansali S, Bhansali SP, Priyanka. A modified open tray implant impression technique for limited mouth opening. J Prosthet Dent 2017 Jan 31. doi: 10.1016/j. prosdent.2016.09.030.

9. Lee H, So JS, Hochstedler JL, Ercoli C. The accuracy of implant impressions: a systematic review. J Prosthet Dent 2008; 100(4): 285-291.

10. Del'Acqua MA, Chávez AM, Compagnoni MA, Molo Fde A Jr. Accuracy of impression techniques for an implantsupported prosthesis. Int J Oral Maxillofac Implants 2010; 25(4): 715-721.

11. Wee AG. Comparison of impression materials for direct multi-implant impressions. J Prosthet Dent 2000; 83(3):323-331

12. Windhorn RJ, Gunnell TR . A simple open-tray implant impression technique.J Prosthet Dent 2006;96(3):220-221.

13. Branemark PI. Osseointegration and its experimental background. J Prosthet Dent 1983; 50(3): 399-410.

14. da Costa HMF, Rodrigues RCS, Mattos MGC, Ribeiro RF. Evaluation of the Adaptation Interface of One-Piece Implant-Supported Superstructures Obtained in Ni-Cr-Ti and Pd-Ag Alloys. Braz Dent J 2003; 14(3): 197-202.

15. Papaspyridakos P, Chen CJ, Gallucci GO, Doukoudakis A, Weber HP, Chronopoulos V. Accuracy of implant impressions for partially and completely edentulous patients: a systematic review. Int $\mathrm{J}$ Oral Maxillofac Implants 2014; 29(4): 836-845.

16. Buzayan MM, Yunus N B. Passive Fit in Screw Retained Multi-unit Implant Prosthesis Understanding and Achieving: A Review of the Literature. J Indian Prosthodont Soc 2014; 14(1): 16-23.

17. Jemt $T$. In vivo measurements of precision of fit involving implant-supported prostheses in the edentulous jaw. Int $\mathbf{J}$ Oral Maxillofac Implants 1996; 11(2): 151-158.

18. Assuncao WG, Gomes EA, Rocha EP, Delben JA. Threedimensional finite element analysis of vertical and angular misfit in implant-supported fixed prostheses. Int J Oral Maxillofac Implants 2011; 26(4): 788-796

19. Sahin S, Cehreli MC. The significance of passive framework fit in implant prosthodontics: current status. Implant Dent 2001; 10(2): 85-92.

20. Rashidan N, Alikhasi M, Samadizadeh S, Beyabanaki E, Kharazifard MJ. Accuracy of implant impression coping 
types and shapes. Clin Implant Dent Relat Res 2012; 14(2): 218-225.

21. Schneider A, Kurtzman GM, Silverstein LH. Improving implant framework passive fit and accuracy through the use of verification stents and casts. J Dent Technol 2001;18(4): 23-25.

22. Kim JH, Kim KR, Kim S. Critical appraisal of implant impression accuracies: A systematic review. J Prosthet Dent 2015; 114(2): 185-192.

23. Alexander Hazboun GB, Masri R, Romberg E, Kempler J, Driscoll CF. Effect of implant angulation and impression technique on impressions of NobelActive implants. J Prosthet Dent. 2015; 113(5): 425-431.

24. Liou AD, Nicholls JI, Yuodelis RA, Brudvik JS . Accuracy of replacing three tapered transfer impression copings in two elastomeric impression materials. Int J Prosthodont 1993; 6(4):377-383.

25. Lee SJ, Gallucci GO. Digital vs. conventional implant impressions: efficiency outcomes. Clin Oral Implants Res 2013; 24(1):111-115.

26. Walker MP, Ries D, Borello B. Implant cast accuracy as a function of impression techniques and impression material viscosity. Int J Oral Maxillofac Implants 2008; 23(4): 669674

27. Faria JC, Silva-Concílio LR, Neves AC, Miranda ME, Teixeira ML. Evaluation of the accuracy of different transfer impression techniques for multiple implants. Braz Oral Res 2011; 25(2): 163-167.

28. Herbst D, Nel JC, Driessen CH, Becker PJ. Evaluation of impression accuracy for osseointegrated implant supported superstructures. J Prosthet Dent 2000; 83(5): 555-561.

29. Auroy P, Nicolas E, Bedouin Y. Torque resistance of impression copings after direct implant impression: An in vitro evaluation of impression materials with and without adhesive. J Prosthet Dent 2017; 117(1): 73-80.

30. Singh S, Kumar A. Implant Impression Techniques in Dentistry J Dent Sci Oral Rehab 2016; 7(3): 137-141

31. Barrett MG, Rijk WG, Burgess JO. The accuracy of six impression techniques for osseointegrated implants. J Prosthodont 1993; 2(2): 75-82

32. Naconecy MM, Teixeira ER, Shinkai RSA, Frasca LCF, Cervieri A. Evaluation of the accuracy of three transfer techniques for implant-supported prostheses with multiple abutments. Int J Oral Maxillofac Implants 2004; 19(2): 192-198

33. Ghanem RA, Nassani MZ, Baroudi K, Abdel Fattah A. Dimensional accuracy of different techniques used for complete-arch multi-implant impressions. J Investig Clin Dent. 2016; 7(3): 225-231.

34. Di Fiore A, Meneghello R, Savio G, Sivolella S, Katsoulis J, Stellini E In Vitro Implant Impression Accuracy Using a New Photopolymerizing SDR Splinting Material. Clin Implant Dent Relat Res 2015; 17 (Suppl 2): e721-729.

35. Yeshwante BJ., Gaikwad SV, Baig N, Patil S, Shaikh WA Comparative evaluation between accuracy of implant impression techniques: A Systematic Review .JDMS 2015; 14(4): 30-36.

36. Daoudi MF, Setchell DJ, Searson LJ: A laboratory investigation of the accuracy of two impression techniques for single-tooth implants. Int J Prosthodont 2001; 14(2): $152-158$

37. Sorrentino R, Gherlone EF, Calesini G, Zarone F. Effect of implant angulation, connection length, and impression material on the dimensional accuracy of implant impressions: an in vitro comparative study. Clin Implant Dent Relat Res 2010; 12(Suppl 1): e63-76.

38. Papaspyridakos P, Lal K. Simple technique to transfer occlusal vertical dimension and articulate a definitive implant cast for a full arch implant prosthesis. J Prosthet Dent 2008; 100(4): 320-322.

39. Frieberg B, Jemt T, Lekholm U. Early failure in 4,641 consecutively placed Bränemark dental implants: a study from stage 1 surgery to the connection of completed prostheses. Int J Oral Maxillofac Implants 1991; 6(2): $142-6$

40. Jaffin R, Berman C. The excessive loss of Bränemark implants in type IV bone: a 5-year analysis. J Periodontol 1991; 62(1): 2-4

41. Reisbeck MH, Matyas J. The accuracy of highly filled elastomeric impression materials. J Prosthet Dent 1975; 33(1): 67-72.

42. McCabe JF, Storer R. Elastomeric impression materials. The measurement of some properties relevant to clinical practice. Br Dent J 1980; 149(3): 73-79

43. Ciesco JN, Malone WFP, Sandrik JL, Mazur B. Comparison of elastomeric impression materials used in fixed prosthodontics. J Prosthet Dent 1981; 45(1): 89-94. 
44. Conrad HJ, Pesun IJ, DeLong R, Hodges JS. Accuracy of two impression techniques with angulated implants. J Prosthet Dent 2007; 97(6):349-356.

45. Cabral LM, Guedes CG. Comparative analysis of 4 impression techniques for implants. Implant Dent 2007; 16(2):187-194.

46. Fernandez MA, Paez de Mendoza CY, Platt JA, Levon JA, Hovijitra ST, Nimmo A . A Comparative Study of the Accuracy between Plastic and Metal Impression Transfer Copings for Implant Restorations. J Prosthodont 2013; 22(5): 367-376.

47. Daoudi MF, Setchell DJ, Searson LJ. An evaluation of three implant level impression techniques for single tooth implant. Eur J Prosthodont Restor Dent 2004; 12(1):9-14.

48. Carr AB. Comparison of impression techniques for a fiveimplant mandibular model. Int J Oral Maxillofac Implants 1991. 6(4): 448-455.

49. Assif D, Marshak B, Schmidt A. Accuracy of implant impression techniques. Int $\mathbf{J}$ Oral Maxillofac Implants 1996; 11(2): 216-222.

50. Balouch F, Jalalian E, Nikkheslat M, Ghavamian R, Toopchi Sh, Jallalian F, Jalalian S. Comparison of Dimensional Accuracy between Open-Tray and Closed-Tray Implant Impression Technique in $15^{\circ}$ Angled Implants $\mathrm{J}$ Dent 2013; 14(3): 96-102.

51. Burawi G, Houston F, Byrne D, Claffey N. A comparison of the dimensional accuracy of the splinted and unsplinted impression techniques for the bone-lock implant system. J Prosthet Dent 1997;77(1):68-75.

52. Stimmelmayr M, Erdelt K, Güth J-F, Happe A, Beuer F. Evaluation of impression accuracy for a four-implant mandibular model-a digital approach. Clin Oral Investig 2012; 16(4):1137-1142.

53. Howell KJ, McGlumphy EA, Drago C, Knapik G. Comparison of the accuracy of biomet $3 \mathrm{i}$ encode robocast technology and conventional implant impression techniques. Int J Oral Maxillofac Implants 2013; 28(1): 228-240.

54. Simeone P, Valentini PP, Pizzoferrato R, Scudieri F. Dimensional accuracy of pickup implant impression: an in vitro comparison of novel modular versus standard custom trays. Int J Oral Maxillofac Implants 2011; 26(3):538-546.
55. Eliasson A, Ortorp A. The accuracy of an implant impression technique using digitally coded healing abutments. Clin Implant Dent Relat Res 2012; 14 (Suppl 1): e30-e38

56. Kwon J-H, Son Y-H, Han C-H, Kim S. Accuracy of implant impressions without impression copings: a three dimensional analysis. J Prosthet Dent 2011; 105(6): 367373 .

57. Jo S-H, Kim K-I, Seo J-M, Song K-Y , Park J-M , Ahn S-G. Effect of impression coping and implant angulation on the accuracy of implant impressions: an in vitro study. $\mathrm{J}$ Adv Prosthodont 2010; 2(4):128-133.

58. Gallucci GO, Papaspyridakos P, Ashy LM, Kim GE, Brady NJ, Weber HP. Clinical accuracy outcomes of closed-tray and open-tray implant impression techniques for partially edentulous patients. Int J Prosthodont 2011; 24(5):469-472

59. Alikhasi M, Siadat H, Monzavi A, Momen-Heravi F. Three dimensional accuracy of implant and abutment level impression techniques: effect on marginal discrepancy. J Oral Implantol 2011; 37: 649-657.

60. Stimmelmayr M, Beuer F, Edelhoff D, Güth JF. Implant Impression Techniques for the Edentulous Jaw: A Summary of Three Studies. J Prosthodont 2016; 25(2):146-150.

61. Moshfeghi M, Tavakoli MA, Hosseini ET, Hosseini AT, Hosseini IT. Analysis of linear measurement accuracy obtained by cone beam computed tomography (CBCTNewTom VG). Dent Res J 2012; 9 (Suppl 1): S57-S62.

62. Moreira AH, Rodrigues NF, Pinho ACM, Fonseca JC, Vilaça JL. Accuracy comparison of implant impression techniques: a systematic review. Clin Implant Dent Relat Res 2015; 17(suppl 2):e751-764.

63. Matta RE, Adler W, Wichmann M, Heckmann SM. Accuracy of impression scanning compared with stone casts of implant impressions J prosthet dent 2017; 117(4): $507-512$.

64. De La Cruz JE, Funkenbusch PD, Ercoli C, Moss ME, Graser GN, Tallents RH. Verification jig for implantsupported prostheses: A comparison of standard impressions with verification jigs made of different materials. J Prosthet Dent 2002; 88(3): 329-336. 